\title{
Assessing the risk of a community outbreak of hepatitis A on blood safety in Latvia, 2008
}

J Perevoščikovs ${ }^{1}$, A Lenglet (annick.lenglet@ecdc.europa.eu)², I Lucenko ${ }^{1}$, A Šteinerte ${ }^{3}$, L Payne Hallström², D Coulombier ${ }^{2}$

1. Latvian State Public Health Agency, Riga, Latvia

2. Preparedness and Response Support Unit, European Centre for Disease Prevention and Control, Stockholm, Sweden

3. State Blood Donor Centre, Riga, Latvia

Citation style for this article:

Perevoščikovs J, Lenglet A, Lucenko I, Šteinerte A, Payne Hallström L, Coulombier D. Assessing the risk of a community outbreak of hepatitis A on blood safety in Latvia, 2008. Euro Surveill. 2010;15(33):pii=19640. Available online: http://www.eurosurveillance.org/ViewArticle.aspx?Articleld=19640

Article published on 19 August 2010

Post-transfusion hepatitis A virus (HAV) infection worldwide is considered a sporadic event. An outbreak of HAV infection occurred in Latvia between the end of 2007 and throughout 2008 with more than 2,800 confirmed cases reported over a 13-month period (incidence of 123 per 100,000 population). The majority of reported HAV infection cases were in people over 18 years of age and in people living in the capital city, Riga. We estimated that the crude risk for HAV contamination of whole blood supplies in Riga between February and October 2008 ranged from 1.4 to 10.6 per 10,000 donated units. In people under 40 years of age, the risk of receiving an infectious blood transfusion was more than 3.0 per 10,000 recipients between August and October 2008 during the peak of the outbreak. We conclude that there is a previously under-recognised impact of HAV on blood safety during widespread outbreaks of this disease. Estimating the risk of contamination of blood supplies during an infectious disease outbreak scenario is important for fine tuning risk assessments and potentially improving public health practices.

\section{Introduction}

Hepatitis A virus (HAV) infection is an acute viral illness usually acquired through the faecal-oral route. Outbreaks have been associated with contaminated food and water supplies, and have also been identified in specific communities such as injecting drug users (IDUs) and men who have sex with men (MSM). The level of endemicity of HAV infection varies worldwide, with higher seroprevalence reported in resourcepoor countries and lower seroprevalence in developed regions such as northern Europe and Japan [1]. In the European Union (EU), the overall notification rate for HAV infection decreased from 15.1 to 2.81 cases per 100,000 from 1996 to 2007 [2]. Despite improved sanitary conditions, but with the lack of universal HAV vaccination programmes in the majority of countries, this disease remains endemic in the EU. However, its epidemiology is changing: EU Member States that were considered previously highly endemic, mostly former east-European countries [3], are now demonstrating moderate endemicity. Such changes in epidemiology are usually characterised by shifts in the population affected from children where HAV infection is asymptomatic or mild, to young adults, in whom the disease is more severe.

Post-transfusion HAV infection has been documented after a person has received whole blood and plasma [4-8], as well as in haemophiliac patients who have received concentrated blood products such as Factor VIII [6,9-17]. In India, blood product recipients are recommended to receive $\mathrm{HAV}$ vaccination and in the United Kingdom, the Department of Health recommends HAV vaccination for haemophiliacs $[18,19]$. Current methods for inactivation of viruses and partition methods for long-lasting blood products are less effective for HAV [20] and parvovirus B19 [21], than for hepatitis $B$ and $C$ viruses, HIV and dengue virus, because HAV and parvovirus $B_{19}$ are non-enveloped protein viruses. However, the general assumption is that blood safety is not greatly affected by HAV and that post-transfusion infection with the virus is a sporadic event, especially in endemic countries where immunity is high.

In Latvia, HAV infection is a notifiable disease through the national surveillance system, using the EU case definition [22]. The incidence of the disease has decreased substantially over the last 20 years, with more than 6,000 cases reported in 1990 (incidence of 263 per 100,000 population), compared with a mean of 87 cases per year between 2000 and 2007 (incidence of four per 100,000 population) [23,24].

In late 2007, surveillance data indicated an increase of reported HAV cases in the country. By December 2008 a total of 2,817 cases had been reported, with 17 deaths [25] (incidence of 123 per 100,000 population). This outbreak was noteworthy in several aspects. Firstly, it was a community-wide outbreak that was concentrated in the capital city, Riga, where $76 \%$ of the cases were reported. Furthermore, the proportion of IDUs among the reported HAV cases was more than $20 \%$ up to July 200; after that, the proportion decreased as the outbreak became increasingly established in the community [25]. Finally, adults were the most affected 
age group of the 1,701 cases reported in Riga between February and October 2008: 1,344 (79\%) cases were aged between 18 and 65 years.

Because of the geographical and age distribution of the majority of cases in this outbreak, we hypothesised that there was a potential impact on blood safety, as the majority of blood donors come from urban areas and are older than 18 years (the minimum age for blood donation, which in Latvia is voluntary). Around $1.3 \%$ of the population regularly donates blood (unpublished data). For this reason we decided to estimate the impact of HAV infection on blood donations during this community-wide outbreak in Latvia.

\section{Methods}

As the majority of HAV infections in Riga were reported between February and October 2008, we divided this time into three distinct outbreak periods (Figure 1): February - April (Period 1), May - July (Period 2) and August - October (Period 3), the last being the peak of the outbreak. On the assumption that $70 \%$ of HAV infections are asymptomatic $[26,27]$ and that all symptomatic infections were reported through the Latvian surveillance system, we calculated the total number of HAV infections in Riga for each of the three outbreak periods (incidence). We also further restricted this analysis to people over 18 years of age (the lower age limit for blood donation in Latvia).

The method used to calculate the risk of HAV contamination of the supply of whole blood in Latvia was based on previous calculations conducted by Biggerstaff and Petersen $[28,29]$ to estimate the impact of West Nile fever outbreaks in the United States on national blood safety. This method considers the proportion of symptomatic and asymptomatic infected cases, the duration of the viraemic period in asymptomatic and symptomatic cases before they develop symptoms (i.e. when they could donate blood) and the duration and attack rate of the outbreak.

The formula used to calculate the mean risk to blood donations is:
To our knowledge, this method has only been used once for other situations, to estimate the impact of a local HAV outbreak on blood safety in France [27]. In order to ensure that our data are comparable, we used the same parameters and assumptions as the French study. On the basis of the parameters from that study and other literature, we assumed that in the Latvian outbreak $70 \%$ of cases were symptomatic, all symptomatic cases were reported through the surveillance system, the duration of pre-symptomatic viraemia in symptomatic cases was 16 days and that the duration of viraemia in asymptomatic cases was 70 days $[26,27,30]$. The crude risk of HAV contamination in blood supplies was then calculated for each of the three outbreak periods.

In order to estimate the risk that a blood transfusion recipient would be susceptible to $\mathrm{HAV}$ infection during this outbreak, we took into account the underlying immunity for HAV in the Latvian population and the screening procedures used at the Latvian blood bank. The anti-HAV seroprevalence of the population was determined in 1998 (unpublished data). In order to estimate the underlying HAV immunity, we extrapolated the seroprevalence data from 1998 by 10 years to estimate seroprevalence levels in 2008 (e.g. we assumed that the seroprevalence of the age group 30-39 years in 1998 would be the level of the 40-49 years age group in 2008 , etc.). We did not take into consideration any additional population immunity resulting from HAV vaccination as this vaccine is not routinely included in the Latvian vaccination schedule and is only available upon individual request. Therefore, we assumed that any population immunity resulting from HAV vaccination would be negligible. Furthermore, blood will not be taken from potential donors at any Latvian blood bank if they report that they have had contact with a person with any infectious disease (including hepatitis A). For those reporting close contact with an HAVinfected person, their blood donation will be deferred for 50 days.

In addition, blood units are tested for alanine aminotransferase (ALT) levels: any donation that contains

Mean risk $=$ Incidence during the outbreak (per 100,000 population) $\times \underline{\text { Mean duration of asymptomatic viraemia (days) }}$ Duration of the outbreak (days)

In order to calculate the mean duration of asymptomatic viraemia, we use the following formula: greater than 90 international units per litre (IU/L) is rejected for donation, as it indicates impaired liver

\section{Mean duration of asymptomatic viraemia $=($ Psympto $\mathrm{x}$ Vsympto $)+($ Pasympto $\mathrm{x}$ Vasympto $)$}

where:

- $\quad$ Psympto $=$ Proportion of symptomatic cases

- Vsympto = Duration of viraemia in symptomatic cases (days)

- Pasympto $=1$ - Psympto $=$ Proportion of asymptomatic cases

- Vasympto = Duration of viraemia in asymptomatic cases (days). function associated with all types of hepatitis. We assumed that in asymptomatic HAV-infected donors, the ALT levels would reach this threshold after 16 days of infection (i.e. the duration of pre-symptomatic viraemia in symptomatic patients) and that their donations would be excluded from the central blood bank. Using the Biggerstaff and Petersen formula we calculated the risk of contamination of blood with HAV using the adjusted asymptomatic viraemic period. This risk was multiplied by the proportion of the population that is 
not immune to hepatitis A, i.e. 1 - [anti-HAV seroprevalence proportion], for a specific age group to obtain the risk of receiving an infectious donation per age group.

\section{Results}

The incidence (per 100,000 population), taking into account asymptomatic and symptomatic cases of HAV infection in Latvia during the three outbreak periods, were calculated to be 32 for Period 1, 52 for Period 2 and 290 for Period 3 . The estimated crude risk for HAVcontaminated whole blood supplies in Latvia between February and October 2008 ranged from 1.4 to 10.6 units per 10,000 donated units (Table 1).

The extrapolated anti-HAV seroprevalence (i.e. immunity) in Latvia in 2008 increased with age, from 15\% in people younger than 15 years to $60 \%$ in people older than 40 years of age (Figure 2 and Table 2). When considering the underlying immunity and the ALT screening at the blood bank, the risk of receiving a contaminated donation and being susceptible for infection was greater than 3.0 per 10,000 transfusions for people younger than 40 years in Riga (Table 2 ).

The Latvian central blood bank received 24,727 valid donations between February and October 2008. Of these, $1.5 \%$ (range: $1.0-2.0 \%$ ) per month had ALT levels greater than $90 \mathrm{IU} / \mathrm{L}$ and were therefore rejected for use. These numbers are similar to those rejected for use before the outbreak was identified. There was one report of possible post-transfusion hepatitis A during the 2008 HAV outbreak, in a hospital in Riga. This person received blood from 28 different donors, none of whom were symptomatic for infection at the time of donation. No further investigations (trace-back or epidemiological) were conducted with the donors to determine their anti-HAV status.

\section{Discussion}

To the best of our knowledge, this is the first time that a national risk assessment of blood safety following a widespread community outbreak of HAV infection in a European country has been conducted. Our study shows that large community outbreaks of an infectious disease such as hepatitis $A$ in a country with a moderate endemicity can have an important and under-recognised impact on blood safety.

There are several limitations in the estimation of risk of contaminated whole blood products with HAV. It is possible that the crude and adjusted risk calculations were overestimated as we considered the overall attack rate of HAV infection in Riga and did not exclude reported cases in infecting drug users. As blood donations from these people would be deferred, they would probably not contribute to contaminated blood supplies. Also,

\section{FIGURE 1}

Confirmed cases of hepatitis A virus infection, Riga, Latvia, January - October 2008 ( $\mathrm{n}=810)$

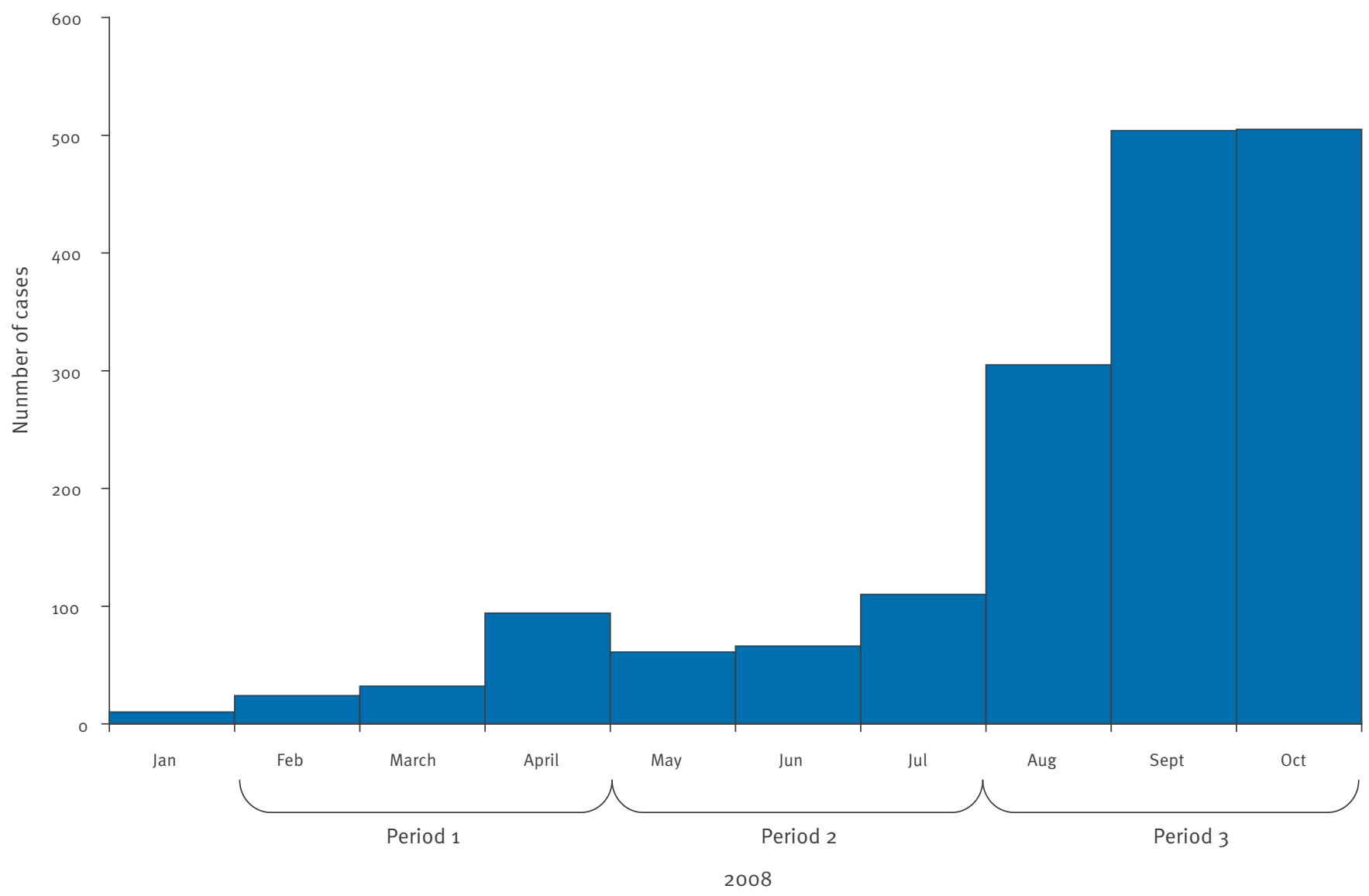


the calculations were unable to take into account the effectiveness of screening procedures that are implemented at the blood bank in Latvia to defer donations from people with a history of contact with someone with an infectious disease. We did not take into consideration the effect of neutralising antibodies in potential donors on reducing the infectious capability of their donated blood, as all available evidence suggest that such antibodies only appear and continue to increase once the person has become symptomatic [30,31]. Their presence would therefore not affect our current risk estimates as a symptomatic potential donor would be excluded from donation at that point. We also could not quantify the effect of HAV-immune donors on the current risk estimates. Furthermore, we were not able to estimate the residual viraemic potential of HAV in blood units or the immunological response of transfusion recipients. Both these factors would modify the risk of post-transfusion HAV infection.

\section{TABLE 1}

Risk of hepatitis A virus contamination of blood donation from donors aged 18-65 years, Riga, Latvia, 2008

\begin{tabular}{|l|c|c|}
\hline Period, 2008 & $\begin{array}{c}\text { Number of HAV-positive } \\
\text { blood donations } \\
\text { per 10,000 blood donations }\end{array}$ & $95 \% \mathrm{Cl}$ \\
\hline 1. February - April & 1.36 & $1.16-1.56$ \\
\hline 2. May - July & 2.03 & $1.80-2.27$ \\
\hline 3. August - October & 10.59 & $10.05-11.13$ \\
\hline
\end{tabular}

$\mathrm{Cl}$ : confidence interval; HAV: hepatitis A virus.

\section{FIGURE 2}

Anti-hepatitis A seroprevalence in 1998 and extrapolated seroprevalence in 2008, by age group, Latvia

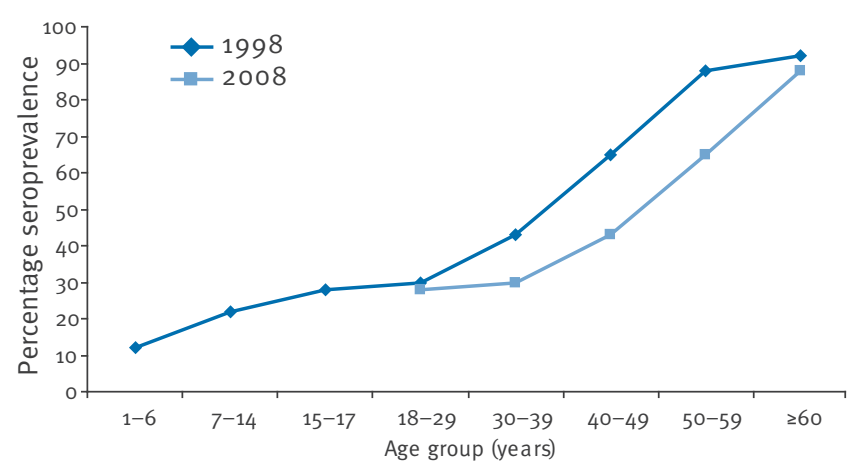

\section{TABLE 2}

Risk of hepatitis A virus infection in recipients of blood donation by age group, Riga, Latvia, August - October, 2008

\begin{tabular}{|l|c|c|c|}
\hline $\begin{array}{l}\text { Age } \\
\text { group of } \\
\text { recipients } \\
\text { (years) }\end{array}$ & $\begin{array}{c}\text { Percentage } \\
\text { of population } \\
\text { immune }\end{array}$ & $\begin{array}{c}\text { Number of HAV } \\
\text { infections per } 10,000 \\
\text { blood donation } \\
\text { recipients }\end{array}$ & $95 \% \mathrm{Cl}$ \\
\hline $0-14$ & 15 & 4.47 & $4.24-4.70$ \\
\hline $15-39$ & 30 & 3.68 & $3.49-3.87$ \\
\hline$\geq 40$ & 60 & 2.10 & $1.99-2.21$ \\
\hline
\end{tabular}

$\mathrm{Cl}$ : confidence interval; HAV: hepatitis A virus.

a Latvian seroprevalance data from 1998 adjusted for 2008.
This study focused only on contamination of whole blood. Long-lasting blood products are produced from pools of blood units (sometimes several thousands) and therefore the risk for contamination would potentially be increased. Also, long-lasting blood products undergo several deactivation steps to eliminate other infectious disease risks. Even though HAV is a nonenveloped virus and the deactivation steps are less effective for this type of virus, it is likely that most viral potential would be removed $[26,30]$. The real risk of contaminated long-lasting blood products during this outbreak in Riga in 2008 is therefore more complex to quantify.

At the peak of the outbreak between August and October 2008, the crude risk for contaminated whole blood supplies was 10.6 per 10,000 donations and the adjusted risk for infective transfusions was greater than 3.0 per 10,000 recipients in people under 40 years. Between February and October 2008, a mean of 2,700 donations per month were made to the Latvian blood bank. Therefore, the calculated risk per 10,000 donations is very similar to the monthly contamination of whole blood supplies during this outbreak.

During a West Nile virus outbreak in the United States in 1999, the calculated risk for transmission of the virus was between 1.8 and 2.7 per 10,000 blood donations [28]. In the light of this estimate, the United States implemented pooled screening of all blood donations for West Nile virus [32]. For other viruses that cause infectious diseases, such as human immunodeficiency virus (HIV) and hepatitis C, the current estimated risk of contamination is one unit per two million donations; for hepatitis B it is one per 200,000 donations [33]. The calculated HAV contamination risk in Riga during this epidemic was significantly higher than the risk of contamination with any of the other mentioned viruses. Over the studied outbreak period, close to 30,000 blood donations were received in Latvia, and it is likely that some of these were contaminated and were not rejected for donation despite routine screening. It is unlikely that the current crude contamination estimation would be reflected in the proportion of donations that exceeded $90 \mathrm{IU} / \mathrm{L}$ of ALT (and would therefore be rejected at the central blood bank), as they only comprise $0.1 \%$ of the total number of donations.

Only one report of possible post-transfusion HAV infection in Latvia was received during the outbreak. This might be explained by the fact that HAV infection is generally not a severe disease and could therefore be missed in patients with serious underlying conditions who receive blood transfusion. Furthermore, it is unlikely that the resources necessary to conduct indepth investigations around this single reported case could be liberated. A stricter follow-up of all transfusion recipients during the outbreak period would have allowed the actual incidence of post-transfusion HAV infection during this outbreak to be determined.

There are measures to prevent infections with HAV through blood transfusion, including vaccination, 
immunoglobulin administration and more stringent screening procedures for possible blood donors. Such methods might need to be temporarily employed during large-scale community outbreaks in order to reduce the risk of HAV infection in transfused patients. However, their use would need to be carefully assessed by comparing the risk of acquiring the infection from contact with a hepatitis A case in the general population versus the risk of acquiring the infection through a blood transfusion as it is possible that the incidence is sufficiently high during the outbreak that a person would be more likely to become infected in the community.

The methods described in this study are one of the possible tools that could facilitate conducting a targeted risk assessment for the impact of an infectious disease on blood supplies during an acute period such as an epidemic. The calculations are simple and easily reproducible for other infectious diseases of epidemic potential. Even though the method has limitations, the estimations of crude and adjusted risks of contamination of whole blood supplies provide important information for the further management of blood donations during an infectious disease outbreak. Combining these rough calculations with other available epidemiological information about the outbreak and complementing these findings with close follow-up of transfusion recipients, the risk assessment might be even further fine-tuned, resulting in better public health practices.

\section{Acknowledgements}

The authors would like to thank Henriette de Valk (French Institute for Public Health Surveillance, Institut de Veille Sanitaire, InVS) and Hans Zaaijer (Sanquin blood-borne infections, the Netherlands) for their technical assistance on this study. We would also like to thank Evelyn Depoortere (ECDC) for the critical revision of this manuscript.

\section{References}

1. World Health Organization (WHO). Hepatitis A. Geneva: WHO; 2000. Available from: http://www.who.int/csr/disease/ hepatitis/HepatitisA_whocdscsredc2000_7.pdf

2. European Centre for Disease Prevention and Control (ECDC). Annual Epidemiological Report on Communicable Diseases in Europe 2008. Stockholm: ECDC; 2008. Available from: http:// www.ecdc.europa.eu/en/publications/Publications/0812 SUR_Annual_Epidemiological_Report_2008.pdf

3. Payne L, Coulombier D. Hepatitis A in the European Union: responding to challenges related to new epidemiological patterns. Euro Surveill. 2009;14(3):pii=19101. Available from: http://www.eurosurveillance.org/ViewArticle. aspx?Articleld $=19101$

4. Lee KK, Vargo LR, Le CT, Fernando L. Transfusion-acquired hepatitis A outbreak from fresh frozen plasma in a neonatal intensive care unit. Pediatr Infect Dis J. 1992;11(2):122-3.

5. Hollinger FB, Khan NC, Oefinger PE, Yawn DH, Schmulen AC, Dreesman GR, et al. Posttransfusion hepatitis type A. JAMA. 1983;250(17):2313-7.

6. Sherertz RJ, Russell BA, Reuman PD. Transmission of hepatitis A by transfusion of blood products. Arch Intern Med. 1984;144(8):1579-80.

7. Rosenblum LS, Villarino ME, Nainan OV, Melish ME, Hadler SC, Pinsky PP, et al. Hepatitis A outbreak in a neonatal intensive care unit: risk factors for transmission and evidence of prolonged viral excretion among preterm infants. J Infect Dis. 1991;164(3):476-82.

8. Bianco C. Hepatitis testing. Immunol Invest. 1995;24(1-2):155-61.

9. Peerlinck K, Vermylen J. Acute hepatitis A in patients with haemophilia A. Lancet. 1993:341(8838):179.
10. Gerritzen A, Schneweis KE, Brackmann $\mathrm{HH}$, Oldenburg I, Hanfland P, Gerlich WH, et al. Acute hepatitis A in haemophiliacs. Lancet. 1992;340(8829):1231-2.

11. Mannucci PM. Outbreak of hepatitis A among Italian patients with haemophilia. Lancet. 1992;339(8796):819.

12. Temperley IJ, Cotter KP, Walsh TJ, Power J, Hillary IB. Clotting factors and hepatitis A. Lancet. 1992;340(8833):1466.

13. Kedda MA, Kew MC, Cohn RJ, Field SP, Schwyzer R, Song E, et al. An outbreak of hepatitis A among South African patients with hemophilia: evidence implicating contaminated factor VIII concentrate as the source. Hepatology. 1995;22(5):1363-7.

14. Centers for Disease Control and Prevention (CDC). Hepatitis A among persons with hemophilia who received clotting factor concentrate--United States, September-December 1995. MMWR Morb Mortal Wkly Rep. 1996;45(2):29-32.

15. Robertson BH, Alter MJ, Bell BP, Evatt B, McCaustland KA, Shapiro CN, et al. Hepatitis $A$ virus sequence detected in clotting factor concentrates associated with disease transmission. Biologicals. 1998;26(2):95-9.

16. Soucie JM, Robertson BH, Bell BP, McCaustland KA, Evatt $B L$. Hepatitis A virus infections associated with clotting factor concentrate in the United States. Transfusion. 1998;38(6):573-9.

17. Chudy M, Budek I, Keller-Stanislawski B, McCaustland KA Neidhold S, Robertson $\mathrm{BH}$, et al. A new cluster of hepatitis A infection in hemophiliacs traced to a contaminated plasma pool. J Med Virol. 1999;57(2):91-9.

18. Arankalle VA, Chadha MS. Who should receive hepatitis $A$ vaccine? J Viral Hepat. 2003;10(3):157-8.

19. Crowcroft NS, Walsh B, Davison KL, Gungabissoon U, PHLS Advisory Committee on Vaccination and Immunisation. Guidelines for the control of hepatitis A virus infection. Commun Dis Public Health. 2001;4(3):213-27.

20. Discussion. Vox sanguinis.1994; 67(S4):24-6.

21. Alter HJ, Stramer SL, Dodd RY. Emerging infectious diseases that threaten the blood supply. Semin Hematol. 2007;44(1):32-41.

22. European Commission. Commission decision of 30 April 2009 amending Decision 2002/253/EC laying down case definitions for reporting communicable diseases to the Community network under Decision No 2119/98/EC of the European Parliament and of the Council. . Official Journal of the European Union. Luxembourg: Publications Office of the European Union. 1.5.2009: L 110/58. Available from: http://eur-lex.europa.eu/ LexUriServ/LexUriServ.do?uri=0J:L:2009:110:0058:0059:EN:P DF

23. Perevoščikovs J. Community wide outbreak of hepatitis $A$ in Latvia in 2008. Riga: Latvian Public Health Agency; 11 November 2008. Presentation. Available from corresponding author.

24. Lanzieri G. Population in Europe 2007: first results. Population and social conditions. Eurostat. Statistics in focus $81 / 2008$. European Communities; 2008. Available from: http://epp. eurostat.ec.europa.eu/cache/ITY_OFFPUB/KS-SF-08-081/EN/ KS-SF-08-081-EN.PDF

25. Perevoscikovs J, Lucenko I, Magone S, Brila A, Curikova J, Vennema H. Community-wide outbreak of hepatitis A in Latvia in 2008 - an update. Euro Surveill. 2009;14(3):pii=19092. Available from: http://www.eurosurveillance.org/ViewArticle. aspx?Articleld $=19092$

26. Bower WA, Nainan OV, Han X, Margolis HS. Duration of viremia in hepatitis A virus infection. J Infect Dis. 2000;182(1):12-7.

27. Brouard C, de Valk $\mathrm{H}$, Pillonel J for the working group Afssaps, EFS, INTS and InVS. [Quantitative estimation of the risk of contamination of donated blood by infectious agents]. SaintMaurice: Institut de Veille Sanitaire; 26 Oct 2007. French. Available from: http://www.invs.sante.fr/publications/2007/ contamination_sang/plaquette_contamination_sang.pdf

28. Biggerstaff BJ, Petersen LR. Estimated risk of West Nile virus transmission through blood transfusion during an epidemic in Queens, New York City. Transfusion. 2002;42(8):1019-26.

29. Biggerstaff BJ, Petersen LR. Estimated risk of transmission of the West Nile virus through blood transfusion in the US, 2002. Transfusion. 2003;43(8):1007-17.

30. Lemon SM. The natural history of hepatitis A: the potential for transmission by transfusion of blood or blood products. Vox sang. 1994;67 Suppl 4:19-23; discussion 4-6.

31. Costa-Mattioli M, Monpoeho S, Nicand E, Aleman MH, Billaudel S, Ferre V. Quantification and duration of viraemia during hepatitis A infection as determined by real-time RT-PCR. J Viral Hepat. 2002;9(2):101-6.

32. Wilder-Smith A, Chen LH, Massad E, Wilson ME. Threat of dengue to blood safety in dengue-endemic countries. Emerg Infect Dis 2009;15(1):8-11.

33. Jarvis WR, Roth VR. Tranfusion-related infection. Cambridge University Press; 2008. 